\title{
COMMENTARY
}

\section{Safer ventilation of the injured lung: one step closer}

\author{
John J Marini* \\ See related research by Bikker et al., http://ccforum.com/content/14/3/R100
}

\begin{abstract}
Prevention of iatrogenic injury due to ventilation of a heterogeneous lung requires knowledge of dynamic regional events occurring within the tidal cycle. Quantitative bedside imaging techniques that are sensitive to regional mechanics and tidal events hold potential for information delivery that cannot be realized by pressure-volume monitoring alone.
\end{abstract}

In the previous issue, Bikker and colleagues demonstrate that electrical impedance tomography has the potential to track regional ventilation responses to decremental positive end-expiratory pressure semiquantitatively in patients with acute lung injury [1], suggesting the potential to predict the consequences of our setting choices. Such innovations are needed, as our search to find a reliable means with which to identify the optimal settings for ventilating acute respiratory distress syndrome remains unaccomplished, more than 40 years after it began $[2,3]$.

Inappropriate values for end-inspiratory or end-expiratory pressure have clear potential to damage a lung predisposed to ventilator-induced lung injury. Furthermore, the driving pressure (the difference between plateau and positive end-expiratory pressures) as well as the rate at which lung inflation occurs (flow magnitude and profile) may be additional keys to safety and hazard [4]. Because we face a heterogeneous mechanical environment and multiple variables to be regulated, our progress toward forging a trustworthy tool with which to adjust respiratory life support in patients afflicted with acute respiratory distress syndrome has been glacially slow.

Over the years, static airway pressures, tidal compliance calculations, contours of the inflation airway pressure-volume curve (inflection points, stress index)

*Correspondence: john.j.marini@healthpartners.com

Regions Hospital MS 11203B, University of Minnesota, 640 Jackson Street, St Paul, MN 55101-2595, USA and, more recently, deflation curve deflection points have been suggested to offer the needed guidance [3,5-7]. Although superficially attractive because airway pressure data are easy to acquire, the idea that any airway pressure-based measurement - used alone - can provide enough information to simultaneously avoid widespread lung overstretch and tidal recruitment seems conceptually naïve.

For the airway pressure to reflect lung characteristics, two conditions must first be met: the chest wall should not contribute unduly to the recorded airway pressure, and respiratory muscle tone must be low. It is sobering to realize that none of the influential clinical trials of ventilatory pattern that now underpin our evidence base assured either pre-requisite. The perceptions that a plateau pressure of $25 \mathrm{cmH}_{2} \mathrm{O}$ is consistently safe or that a plateau exceeding $35 \mathrm{cmH}_{2} \mathrm{O}$ is always dangerous are thus suspect, no matter what the population-based means of clinical trials might suggest [8]. At the bedside we simply do not have all relevant data to specify precise thresholds of this type that are relevant to the individual patients we treat.

In a similar vein, the contours of the airway pressure curve are also unreliable. For example, the stress index a mathematical indicator of the inspiratory pressurevolume curve shape over the tidal range [7] - can work well enough when the lungs are mechanically uniform and/or are free of their confining chest wall, but it, too, cannot be relied upon when those conditions are not assured.

Esophageal pressure, an indicator of the changes in pleural pressure immediately adjacent to the balloon, has a clear rationale for clinical deployment [9]. Used experimentally for more than 40 years [10], the esophageal pressure allows the clinician to estimate the average transpulmonary pressure across the inherently passive lung, addressing many concerns regarding chest wall and muscle tone/effort that plague the application of unmodified airway pressure. All this assumes that such estimates of pleural pressure accurately reflect the interstitial pressure surrounding each vulnerable lung unit - which, unfortunately, is not true. Furthermore, the esophageal pressure-sensed pleural pressure may differ considerably from those remote from it. Moreover, the 
relevant parameters for preventing damage are likely to be tissue tension and strain, which imperfectly relate to the pressure applied across the lung unit.

Another attractive approach to lung protection is to measure absolute lung volume at functional residual capacity, and then to adjust the tidal volume to the actual size of the aerated baby lung [11]. Because the specific elastance of the aerated lung compartment in acute lung injury/acute respiratory distress syndrome appears similar to that of healthy tissue and independent of lung size, the ratio of the tidal volume to functional residual capacity holds promise to identify the appropriate breath size - once an appropriate positive end-expiratory pressure level has been selected. Inherent in this approach - as well as in all of the above-mentioned approaches to adjusting the ventilatory pattern - is the assumption that the lung is mechanically uniform, so that one parameter reflects the stresses and strains applied to every lung unit. This assumption is seldom defensible. In fact, we may need eventually to employ imaging methodology to satisfy both requirements of avoiding unnecessary overstretch and tidal recruitment in all lung regions of our sickest patients.

As shown by the study of Bikker and colleagues [1], bedside imaging methods that address lung heterogeneity and the dynamics of inflation are at the brink of deployment. Vibration response [12], acoustic mapping [13] and electrical impedance tomography [14] are all in the advanced stages of development. Each technique has the potential for helping us acquire relevant data for managing a heterogeneous and dynamic clinical problem we cannot avoid. As these methods are perfected, useful quantitative indicators are extracted, and general agreement is reached regarding the implications of their information, we will draw considerably closer to our long-pursued goal of how to find the optimal operating range for ventilatory support.

\section{Competing interests}

The author declares that he has no competing interests.
References

1. Bikker I, Leonhardt S, Reis M, Miranda D, Bakker J, Gommers D: Bedside measurement of changes in lung impedance to monitor alveolar ventilation in dependent and non-dependent parts by electrical impedance tomography during a positive end-expiratory pressure trial in mechanically ventilated intensive care unit patients. Crit Care 2010, 14:R100.

2. Petty TL, Ashbaugh DG: The adult respiratory distress syndrome - clinical features, factors influencing prognosis, and principles of management. Chest 1971, 70:233-239.

3. Caramez MP, Kacmarek RM, Helmy M, Miyoshi E, Malhotra A, Amato MB, Harris RS: A comparison of methods to identify open-lung PEEP. Intensive Care Med 2009, 35:740-747.

4. Rich PB, Reichert CA, Sawada S, Awad SS, Lynch WR, Johnson KJ, Hirschl RB: Effect of rate and inspiratory flow on ventilator-induced lung injury. J Trauma 2000, 49:903-911.

5. Suter PM, Fairley B, Isenberg MD: Optimum end-expiratory airway pressure in patients with acute pulmonary failure. N Engl J Med 1975, 292:284-289.

6. Albaiceta GM, Luyando LH, Parra D, Menendez R, Calvo J, Rodríguez PP, Taboada F: Inspiratory vs. expiratory pressure-volume curves to set endexpiratory pressure in acute lung injury. Intensive Care Med 2005, 31:1370-1378.

7. Grasso S, Terragni P, Mascia L, Fanelli V, Quintel M, Herrmann P, Hedenstierna G, Slutsky A, Ranieri V: Airway pressure-time curve profile (stress index) detects tidal recruitment/hyperinflation in experimental acute lung injury. Crit Care Med 2004, 32:1018-1027.

8. Hager DN, Krishnan JA, Hayden DL, Brower RG: Tidal volume reduction in patients with acute lung injury when plateau pressures are not high. Am J Respir Crit Care Med 2005, 172:1241-1245.

9. Talmor D, Sarge T, Malhotra A, O'Donnell CR, Ritz R, Lisbon A, Novack V, Loring $\mathrm{SH}$ : Mechanical ventilation guided by esophageal pressure in acute lung injury. N Engl J Med 2008, 359:2095-2104.

10. Milic-Emili J, Mead J, Turner JM, Glauser EM: Improved technique for estimating pleural pressure from esophageal balloons. J Appl Physiol 1964, 19:207-211.

11. Chiumello D, Carlesso E, Cadringher P, Caironi P, Valenza F, Polli F, Tallerini F, Cozzi P, Cressoni M, Colombo A, Marini JJ, Gattinoni L: Lung stress and strain during mechanical ventilation of the acute respiratory distress syndrome. Am J Respir Crit Care Med 2008, 178:346-355.

12. Dellinger RP, Jean S, Cinel I, Tay C, Susmita R, Glickman YA, Parrillo JE: Regional distribution of acoustic-based vibration as a function of mechanical ventilation mode. Crit Care 2007, 11:R26.

13. Lichtenstein D, Goldstein G, Mourgeon E, Cluzel P, Gernier P, Rouby JJ: Comparative diagnostic performances of auscultation, chest radiography and lung ultrasonography in acute respiratory distress syndrome. Anesthesiology 2004, 100:9-15.

14. Meier T, Luepschen $H$, Karsten J, Leibecke T, Grossherr M, Gehring H, Leonhardt S: Assessment of regional lung recruitment and derecruitment during a PEEP trial based on electrical impedance tomography. Intensive Care Med 2008, 34:543-550.

doi:10.1186/cc9028

Cite this article as: Marini JJ: Safer ventilation of the injured lung: one step closer. Critical Care 2010, 14:192. 